\title{
Avaliação das Propriedades de Misturas de Poliestireno com Oligômeros de Poli(Óxido de Propileno) e Poliestireno.
}

\author{
Maria Andréa P. R. Torres, Michelle T. Telles e Clara Marize F. Oliveira
}

Resumo: Misturas poliméricas de poliestireno (PS1) com poli(óxido de propileno) (PPO) e de poliestireno (PS1) com poliestireno de baixíssima massa molecular (PS2), foram preparadas, em diversas composições, para avaliação das propriedades térmicas, mecânicas e de escoamento. As propriedades térmicas foram avaliadas por calorimetria diferencial de varredura (DSC) e as propriedades mecânicas e de escoamento foram determinadas através de ensaios de tração e monitoração do valor do torque durante o processamento das misturas, respectivamente. Foi observado que o PPO atua como plastificante do poliestireno enquanto que o PS2 não apresenta este comportamento. Entretanto, a adição de ambos os componentes produz mudança no empacotamento molecular, originando o aparecimento de fissuras na superfície dos materiais.

Palavras-chave: Misturas poliméricas, poliestireno, poli(óxido de propileno), fissuras, oligômeros.

\section{Introdução}

O poliestireno (PS1) é um dos termoplásticos mais consumidos devido ao seu baixo custo, transparência e boas propriedades elétricas, sendo utilizado em diversos segmentos do mercado de plásticos. Entretanto, é um material rígido, limitando sua aplicação quando é requerida boa resistência ao impacto ${ }^{[1]}$.

A utilização de misturas poliméricas tem sido muito empregada para obter materiais com desempenhos específicos, impossíveis de serem atingidos com o uso de apenas um polímero. Geralmente, as misturas que combinam dois polímeros amorfos são produzidas devido ao baixo custo e à obtenção de discretas mudanças de propriedades. No caso de polímeros rígidos, a adi- ção de oligômeros pode resultar na preparação de materiais mais flexíveis, devido à plastificação externa. Esta é uma técnica considerada econômica e versátil ${ }^{[2-6]}$.

A adição de moléculas de baixa massa molecular a um polímero rígido resulta, geralmente, na diminuição da temperatura de transição vítrea $\left(\mathrm{T}_{\mathrm{g}}\right)$, diminuindo a temperatura de processamento. Além disso, geralmente, ocorre decréscimo no valor do módulo de elasticidade do polímero, aumentando sua tenacidade. Entretanto, a adição de pequena quantidade de plastificante pode ocasionar a antiplastificação do polímero $^{[7,8]}$. Neste caso, a adição de oligômeros resulta no aumento do valor do módulo de elasticidade, que pode ser causado por diversos fatores, como a diminuição do volume livre do polímero ${ }^{[9-14]}$. 
De acordo com a literatura, a plastificação em termoplásticos rígidos pode facilitar o aparecimento de fissuras na superfície do polímero, prejudicando suas propriedades mecânicas ${ }^{[13,14]}$.

Este trabalho avalia a influência da adição de oligômero de poli(óxido de propileno) (PPO) e também de poliestireno de baixíssima massa molecular (PS2) ao poliestireno comercial (PS1). O PPO é muito utilizado industrialmente como lubrificante e tensoativo ${ }^{[15]}$.

\section{Parte Experimental}

\section{Materiais}

O poliestireno (PS1) $\left[\mathrm{M}_{\mathrm{n}}=111.000 \mathrm{~g} / \mathrm{mol}\right.$, obtido por cromatografia de permeação em gel, [GPC] e o poliestireno de baixíssima massa molecular (PS2) $\left[\mathrm{M}_{\mathrm{n}}=4.500 \mathrm{~g} / \mathrm{mol}\right.$, obtido por GPC $]$ foram gentilmente cedidos pela EDN-Poliestireno do Sul Ltda. e EDNEstireno do Nordeste Ltda., respectivamente; o poli(óxido de propileno) (PPO) $\left[\mathrm{M}_{\mathrm{n}}=890 \mathrm{~g} / \mathrm{mol}\right.$, obtido por osmometria de pressão de vapor] foi gentilmente cedido pela Dow Química S.A.

\section{Método de preparo}

As misturas PS1/PPO e PS1/PS2 foram preparadas utilizando-se uma câmara de mistura Haake modelo Rheomix 600, variando-se a quantidade de PPO e PS2 de 1 a $10 \%$ (em massa). As misturas citadas anteriormente, foram processadas a $160^{\circ} \mathrm{C}$, utilizando-se rotores do tipo "roller blades" à velocidade de rotação de 40$50 \mathrm{rpm}$ por 10 minutos, sendo que o PS2 e o PPO foram adicionados 8 minutos após a adição do PS1.

\section{Caracterização}

O monitoramento do torque foi feito durante o preparo das misturas a fim de avaliar o efeito da adição de oligômeros no processamento do PS1.

As massas poliméricas obtidas após o processamento foram analisadas por calorimetria diferencial de varredura (DSC) para avaliação da mobilidade molecular das misturas, determinandose suas respectivas temperaturas de transição vítrea. As condições de análise utilizadas foram: faixa de temperatura: -25 a $150^{\circ} \mathrm{C}$; razão de aquecimento: $10^{\circ} \mathrm{C} / \mathrm{min}$ e razão de resfriamento: $200^{\circ} \mathrm{C} / \mathrm{min}$.

As propriedades mecânicas foram avaliadas por ensaios de tração segundo a norma ASTM 882-83, utilizando-se dinamômetro Instron modelo 4201. Os corpos de prova (com dimensões 100x 80x 0,95 mm) foram obtidos através de moldagem por compressão das massas poliméricas a $150^{\circ} \mathrm{C}$ durante 5 minutos. Os ensaios foram realizados utilizando-se distância de separação das garras de $50 \mathrm{~mm}$ e velocidade de separação das garras de $1 \mathrm{~mm} / \mathrm{min}$.

\section{Resultados e Discussão}

Análise da mobilidade molecular das misturas de PS1/PPO e PS1/PS2 por calorimetria diferencial de varredura

A Figura 1 apresenta os resultados obtidos por DSC e revelam que o PS2 não atua como plastificante, pois não houve variação no valor da temperatura de transição vítrea das misturas de PS1/PS2 em relação ao PS1 puro. Entretanto, no caso das misturas de PS1/ PPO pode ser concluído que houve diminuição significativa no valor da $T_{g}$ em relação ao PS 1 puro, sugerindo que o PPO atua como plastificante.

Avaliação da influência da adição de PPO no processamento do PS1

O estudo relacionado ao efeito da adição de PPO ao PS1 foi realizado através do monitoramento das curvas de torque obtidas durante o processamento das misturas. As curvas relativas às misturas de PS1/PPO, contendo 1,5 e $10 \%$ (em massa) de PPO, estão apresentadas na Figura 2. Pode ser observado que o PPO atua como

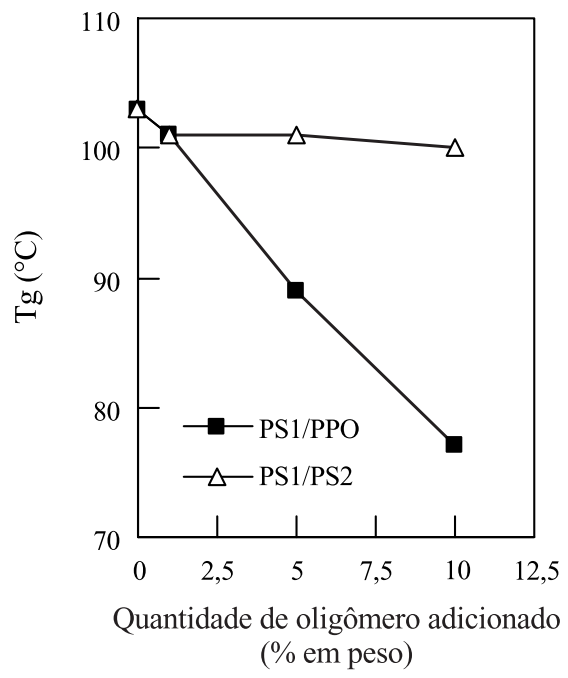

Figura 1. Variação da temperatura de transição vítrea das misturas de PS1/PPO e PS1/PS2 de acordo com a quantidade de oligômero adicionado 


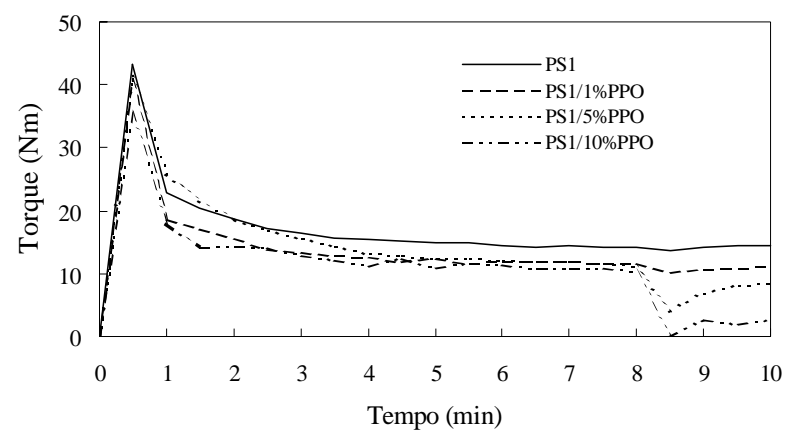

Figura 2. Curvas de torque $\mathrm{x}$ tempo para misturas de PS1/PPO. Foram utilizados valores de torque com tempo e programa Excel 5.0

plastificante, pois ocorre diminuição significativa nos valores de torque à medida que a quantidade de PPO aumenta, comparado-se ao PS1 puro processado nas mesmas condições de preparo das misturas.

Avaliação da influência da adição de PS2 no processamento do PS1

Analogamente ao estudo anterior, foi feita a monitoração das curvas de torque obtidas durante o processamento das misturas de PS1/PS2, utilizandose 1,5 e $10 \%$ (em massa) de PS2. Estas curvas estão apresentadas na Figura 3 e pode ser observado que, diferente do PPO, o PS2 não atua como plastificante, pois a adição de PS2 não ocasiona diminuição significativa no valor do torque, se comparado ao PS1 puro processado nas mesmas condições de preparo das misturas. Este resultado sugere que o PS2 pode melhorar a processabilidade do PS1 sem ocasionar diferenças significativas em suas propriedades físicas e térmicas.

Comparando os resultados apresentados nas Figuras 2 e 3, pode ser verificado que para aumentar a processabilidade do PS1 é necessário adicionar menor quantidade de PPO se comparado ao PS2. Pode ser observado que a redução do valor do torque das misturas de PS1/PPO e PS1/PS2 é mais acentuada para as composições 90/10.

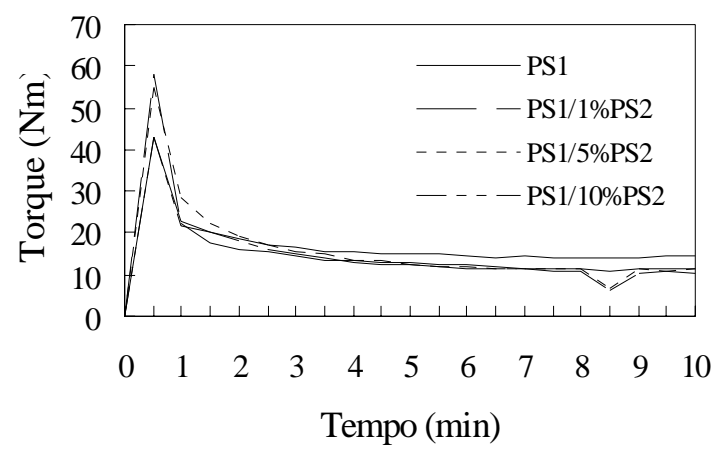

Figura 3. Curvas de torque $x$ tempo para misturas de PS1/PS2. Foram utilizados valores de torque com tempo e programa Excel 5.0
Avaliação das propriedades mecânicas das misturas PS1/PPO e PS1/PS2

As propriedades mecânicas obtidas por ensaios de tração encontram-se relacionadas nas Figuras 4, 5 e 6.

As Figuras 4 e 5 relacionam a variação do módulo de elasticidade e da resistência à tensão na ruptura de acordo com a composição das misturas de PS1/PPO e PS1/PS2, respectivamente. Pode ser observada a diminuição dos valores de resistência à tensão na ruptura e módulo de elasticidade das misturas de PS1/ PPO com o aumento da quantidade de PPO até a com-

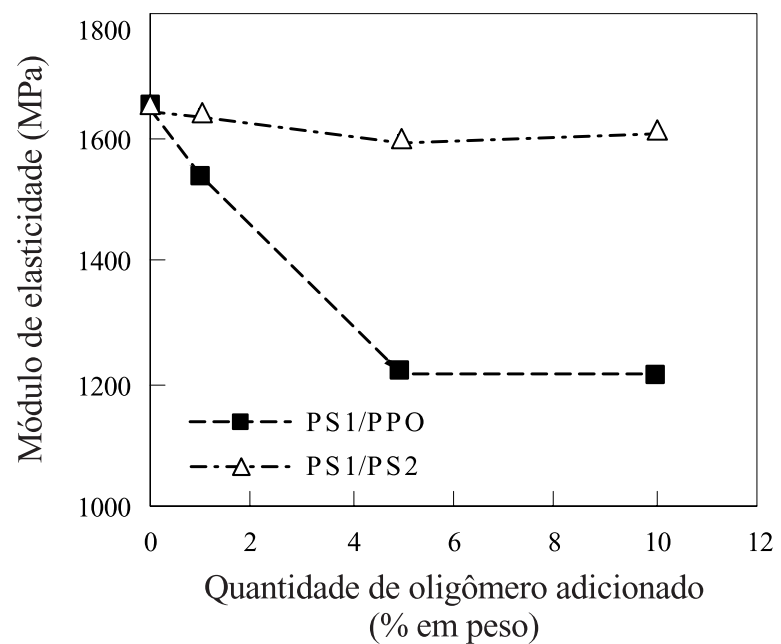

Figura 4. Variação do módulo de elasticidade para as misturas de PS1/ PPO e PS1/PS2

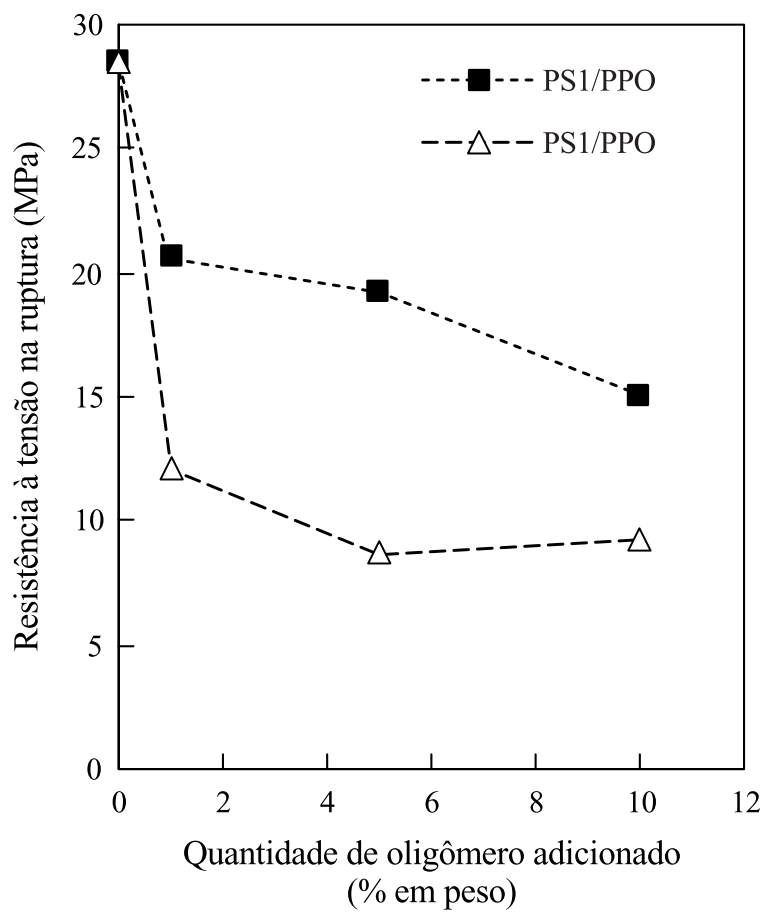

Figura 5. Variação da resistência à tensão na ruptura para as misturas de PS1/PPO e PS1/PS2 


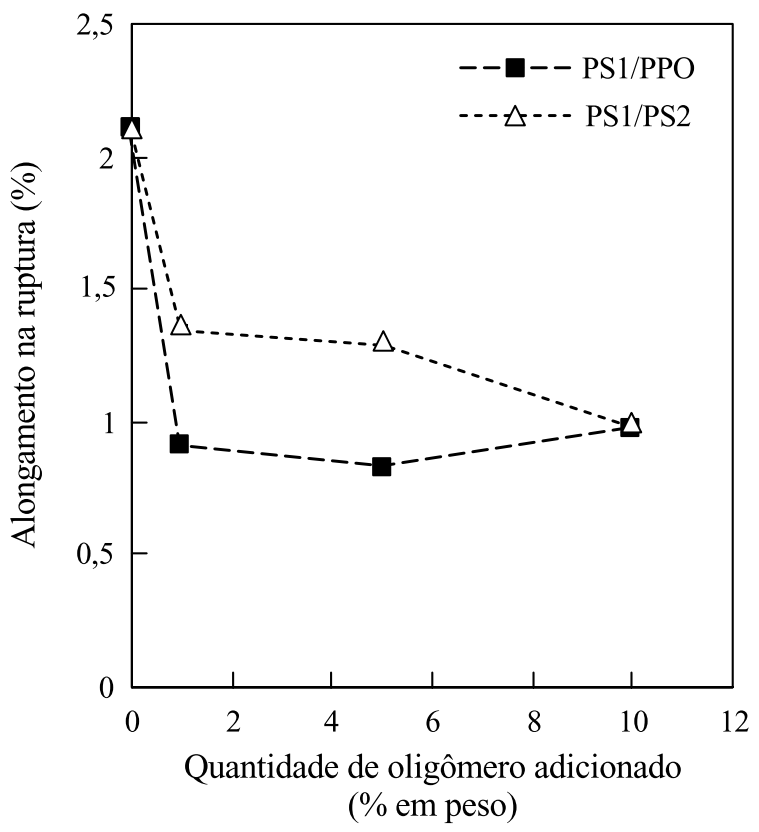

Figura 6. Variação do alongamento na ruptura para as misturas de PS1/ PPO e PS1/PS2

posição 95/5. Pode ser verificado também que a adição de PS2 ao PS1 provoca mudanças significativas nos valores de resistência à tensão na ruptura e módulo de elasticidade.

A Figura 6 apresenta a variação do alongamento na ruptura de acordo com a composição das misturas de PS1/PPO e PS1/PS2. Estes resultados revelam que a adição de PPO ao PS1 ocasionou diminuição no valor de alongamento na ruptura, indicando que a plasticidade conferida ao PS1 pelo PPO produz uma reordenação, diminuindo o volume livre existente entre as moléculas e, conseqüentemente, as misturas de PS1/PPO tornaram-se mais quebradiças que o PS1. De acordo com trabalhos anteriores ${ }^{[5,6,16-18]}$, pode ser sugerido que as propriedades mecânicas das misturas de PS1/PPO foram inferiores às do PS1, devido ao provável aparecimento de fissuras perpendiculares à direção da orientação molecular produzida durante o processamento. Pode ser observado também que a adição de PS2 ao PS1 ocasionou diminuição no valor de alongamento na ruptura, contudo o efeito na diminuição desses valores foram menos significativos do que os obtidos com o PPO. Logo, os resultados sugerem que o PS2 não se comporta como plastificante mas que pode produzir uma mudança no empacotamento molecular, criando sítios rígidos de concentrações de tensões a partir dos quais as fissuras podem aparecer rapidamente na superfície do material, como relatado anteriormente ${ }^{[19]}$.

\section{Conclusões}

Neste trabalho, pode ser avaliada a diminuição dos valores de torque e da $\mathrm{T}_{\mathrm{g}}$ das misturas de PS1/PPO em relação ao PS1 e, no caso da adição de PS2 ao PS1, foi verificado que não houve mudança significativa destas variáveis em relação ao PS1. Estes resultados sugerem que para melhorar a processabilidade do PS1 é necessária a adição de menor quantidade de PPO do que de PS2 e que o PPO atua como plastificante.

Foi verificado, também, que a adição de PPO ou PS2 ao PS1 ocasionou diminuição nos valores de módulo de elasticidade e de resistência à tensão. Contudo, não houve aumento do valor de alongamento na ruptura. Pode ser observado que este efeito foi mais significativo para as misturas de PS1/PPO.

Este estudo sugere que a adição de PPO ou PS2 ao PS1, provavelmente, ocasionou mudança no rearranjo molecular, acelerando o aparecimento de fissuras na superfície dos materiais, tornando os materiais obtidos mais quebradiços.

\section{Agradecimentos}

Os autores agradecem ao Conselho Nacional de Desenvolvimento Científico e Tecnológico (CNPq) e ao Conselho de Ensino para Graduados e Pesquisa (CEPG-UFRJ) pelo apoio financeiro recebido, e às Empresas citadas na parte experimental pela doação dos polímeros utilizados neste estudo.

\section{Bibliografia}

1. Corazza Filho, E. C. - "Poliestireno: O material e sua transformação", 2a ed., São Paulo: Plásticos em Revista, 1987, p. 18.

2. Kienzle, S. Y. - "Properties modification by use of polymer-polymer mixtures" em Handbook of Engineering Plastics, v.2, ASM Internacional, 1988, p. 487.

3. Wilson, A. S. - Rapra Review, Report 88, 8, 3-9 (1996).

4. Leadbitter, J.; Day, J. A. e Ryan, J. L. - Rapra Review, Report 78, 7, 20-25 (1994).

5. Torres, M. A. P. R.; Oliveira, C. M. F.; Menezes, S. M. C. e Tavares, M. I. B. - "Efeito da adição 
de poliestireno de baixo peso molecular e poli(óxido de propileno) ao poliestireno por RMN no estado sólido", Anais do VI Encontro de Usuários de Ressonância Magnética Nuclear, Rio de Janeiro, Universidade Federal do Rio de Janeiro,1997, p. 47.

6. Volkov, I. O.; Gorelova, M. M.; Pertsin, A. J.; Filimonova, L. V.; Torres, M. A. R. e Oliveira, C. M. F. - J. Appl. Polym. Sci., 68, 517-522 (1998).

7. Sjoerdsma, S. D. - Polymer, 27, 164-168 (1986).

8. Heikens, D.; Hoen, N.; Barentsen, W.; Piet, P. e Ladan, H. - J. Polym. Sci.: Polym. Symp., 62, 309-341 (1986).

9. Smith, P. B.; De Lassus, P. T.; Ellaboudy, A. S.; Diedering, D. E. e Landes, B. G. - Macromol. Symp., 86, 193-211 (1994).

10. Costa, D. A. - "Estudo das propriedades da mistura física de nylon-6 e poli(óxido de propileno)", Tese de Mestrado, Universidade Federal do Rio de Janeiro, Rio de Janeiro, (1991).

11. Jackson Jr., W. J. e Caldwell, J. R. - J. Appl. Polym. Sci., 11, 211-226 (1967).

12. Kinjo, N. e Nakagawa, T. - Polym. J., 4, 143-153 (1973).
13. Costa, D. A. e Oliveira, C. M. F. - Polymer Testing, 13, 205-210 (1994).

14. Jackson Jr., W. J. e Caldwell, J. R. - J. Appl. Polym. Sci., 11, 227-244 (1967).

15. Gagnon, S. D. - "1,2-Epoxide polymers" em Encyclopedia of Polymer Science and Engineering; H. F. Mark, N. M. Bikales, C. G. Overberger, G. Menges; New York, John Wiley \& Sons, v.6, 1985, p. 273.

16. Torres, M. A. P. R. - "Estudo das propriedades de misturas físicas de poliestireno e poli(óxido de propileno)", Tese de Mestrado, Universidade Federal do Rio de Janeiro, Rio de Janeiro, (1996).

17. Engel, L.; Klingele, H.; Ehrenstein, G. W. e Schaper, H. - An Atlas of Polymer Damage, Vienna, Wolfe Science Books, 1978, p. 7.

18. Anderson, S. L.; Grulke, E. A.; DeLassus, P. T.; Smith, P. B.; Kocher, C. W. e Landes, B. G. Macromolecules, 28, 2944-2954 (1995).

19. Warty, S.; Morrow, D. R. e Sauer, J. A. - Polymer, 19, 1465-1472 (1978).

Recebido: 28/05/97 Aprovado: 10/06/98 